\title{
Activation of AMPK by OSU53 protects spinal cord neurons from oxidative stress
}

\author{
Jun $X u^{1}$, Liang $W_{u^{1}}{ }^{*}$, Yiming Zhang ${ }^{1}$, Huijie Gu ${ }^{1}$, Zhongyue Huang ${ }^{1}$, Kaifeng Zhou ${ }^{1}$ \\ and Xiaofan Yin ${ }^{1}$ \\ ${ }^{1}$ Department of Orthopedics, Minhang Hospital, Fudan University, Shanghai, China \\ *Co-First author
}

Correspondence to: Xiaofan Yin, email: yxfgkysgj7@163.com

Keywords: spinal cord injury, oxidative stress, AMPK and OSU53

Received: July 27, $2017 \quad$ Accepted: August 28, $2017 \quad$ Published: October 23, 2017

Copyright: $\mathrm{Xu}$ et al. This is an open-access article distributed under the terms of the Creative Commons Attribution License 3.0 (CC BY 3.0), which permits unrestricted use, distribution, and reproduction in any medium, provided the original author and source are credited.

\section{ABSTRACT}

The present study tested the potential effect of OSU53, a novel AMPK activator, against hydrogen peroxide ( $\mathrm{H2O2}$ )-induced spinal cord neuron damages. Treatment with OSU53 attenuated $\mathrm{H2O2}$-induced death and apoptosis of primary murine spinal cord neurons. OSU53 activated AMPK signaling, which is required for its actions in spinal cord neurons. The AMPK inhibitor Compound C or AMPKa1 siRNA almost abolished OSU53-mediated neuroprotection against $\mathrm{H} 2 \mathrm{O2}$. On the other hand, sustained-activation of AMPK by introducing the constitutive-active AMPKa1 mimicked OSU53's actions, and protected spinal cord neurons from oxidative stress. OSU53 significantly attenuated $\mathrm{H2O2}$-induced reactive oxygen species production, lipid peroxidation and DNA damages in spinal cord neurons. Additionally, OSU53 increased NADPH content and heme oxygenase-1 mRNA expression in H2O2-treated spinal cord neurons. Together, we indicate that targeted-activation of AMPK by OSU53 protects spinal cord neurons from oxidative stress.

\section{INTRODUCTION}

Oxidative stress following the spinal cord injury is a main cause of secondary damages to neurons [1-3]. The levels of different reactive oxygen species (ROS), i.e. superoxide anion, hydroxyl free radicals and hydrogen peroxide $\left(\mathrm{H}_{2} \mathrm{O}_{2}\right)$, are significantly increased in the spinal cord following traumatic and non-traumatic injuries [4]. ROS production shall led to a number of harmful effects, including lipid peroxidation, protein oxidation, DNA damage, and eventually spinal cord neuronal death and apoptosis [1-4].

AMPK (AMP-activated protein kinase) is a key regulator of cellular energy $[5,6]$. This heterotrimeric serine-threonine protein kinase is activated under energy crisis, which helps to maintain energy homeostasis $[5,6]$. There are three AMPK subunits: $\alpha$ catalytic subunit along with $\beta$ and $\gamma$ regulatory subunits. Phosphorylation on Thr172 at the $\alpha$ subunit is pivotal for AMPK activation $[5,6]$. Recent studies have focused the pro-survival function of AMPK. AMPK activates/inactivates its downstream effectors to promote cell survival under stress conditions [7-11]. For example, activated AMPK protects cells from oxidative stress by increasing NADPH (nicotinamide adenine dinucleotide phosphate) content [7-9]. Additionally, AMPK-activated cell autophagy could also be pro-survival $[8,10,11]$.

Recently research efforts have developed a novel small-molecule AMPK activator, namely OSU53 [12]. Unlike other known AMPK activators (i.e. AICAR [13] and aspirin [14]), OSU53 binds directly to the $\alpha$ subunit, which activates AMPK with an excellent EC-50 (around $1-10 \mu \mathrm{M})$ [15-17]. Meanwhile, OSU53 displays fine oral bioavailability, which is delivered in its metabolically active state (no further modification is needed) [15-17]. The current study tested its potential effect in spinal cord neurons against oxidative stress.

\section{RESULTS}

OSU53 protects murine spinal cord neurons from $\mathrm{H}_{2} \mathrm{O}_{2}$

To mimic oxidative stress in vitro, primary cultured murine spinal cord neurons were treated with hydrogen peroxide $\left(\mathrm{H}_{2} \mathrm{O}_{2}\right)$ at different concentrations, from 50 
$400 \mu \mathrm{M}$. Cell Counting Kit-8 (CCK-8) assay results in Figure 1A demonstrated that $\mathrm{H}_{2} \mathrm{O}_{2}$ dose-dependently inhibited survival of the murine spinal cord neurons. The CCK-8 optic density (OD) value was decreased significantly following $100-400 \mu \mathrm{M}$ of $\mathrm{H}_{2} \mathrm{O}_{2}$ treatment (at 24 hours, Figure 1A). Significantly, co-treatment with OSU53 $(10 \mu \mathrm{M})$, the novel AMPK activator $[18,19]$, significantly inhibited spinal cord neuron viability (CCK8 OD) reduction (Figure 1A). For instance, the CCK-8 OD of the neurons decreased to $38.93 \pm 2.18 \%$ of control level after $\mathrm{H}_{2} \mathrm{O}_{2}(200 \mu \mathrm{M}, 24$ hours $)$ treatment. Following OSU53 $(10 \mu \mathrm{M})$ co-treatment, its level recovered to 76.47 $\pm 5.30 \%$ of control level (Figure 1A).

Decreased cell survival could be due to cell death. The release of lactate dehydrogenase (LDH) to the conditional medium is the well-established marker of cell death. We here demonstrated that treatment with 100 $400 \mu \mathrm{M}$ of $\mathrm{H}_{2} \mathrm{O}_{2}$ significantly increased medium LDH release, suggesting spinal cord neuronal death (Figure 1B). Such cytotoxic effect was again largely attenuated with co-treatment of OSU53 $(10 \mu \mathrm{M})$ (Figure 1B). The potential dose response of OSU53 was also tested. As demonstrated in Figure 1C, co-treatment with OSU53 at $1-10 \mu \mathrm{M}$ significantly attenuated $\mathrm{H}_{2} \mathrm{O}_{2}(200 \mu \mathrm{M})$-induced viability reduction of the spinal cord neurons. At a lower concentration $(0.5 \mu \mathrm{M})$, this novel AMPK activator was in-effective against $\mathrm{H}_{2} \mathrm{O}_{2}$ (Figure 1C), thus confirming a dose-dependent response. Collectively, these results suggest that OSU53 protects murine spinal cord neurons from $\mathrm{H}_{2} \mathrm{O}_{2}$.

\section{OSU53 inhibits $\mathrm{H}_{2} \mathrm{O}_{2}$-induced spinal cord neuron apoptosis}

Next, the potential effect of OSU53 on $\mathrm{H}_{2} \mathrm{O}_{2}$-induced neuronal apoptosis was analyzed. As shown in Figure 2A, treatment with $\mathrm{H}_{2} \mathrm{O}_{2}(200 \mu \mathrm{M})$ in cultured murine spinal cord neurons induced cleavage of both caspase-9 and PARP [poly (ADP-ribose) polymerase]. Meanwhile, the caspase-9 activity was also increased in $\mathrm{H}_{2} \mathrm{O}_{2}$-treated neurons (Figure 2B). Such actions by $\mathrm{H}_{2} \mathrm{O}_{2}$ were largely attenuated with co-treatment of OSU53 (Figure 2A-2B). Additionally, $\mathrm{H}_{2} \mathrm{O}_{2}$ stimulation in the neurons also induced production of single strand DNA ("ssDNA") (Figure 2C), mitochondrial depolarization (Figure 2D, JC-1 OD increase [20]) and TUNEL (terminal transferase uridyl nick end labeling) nuclei increase (Figure 2E), which all largely attenuated by OSU53. Therefore, these results suggest that OSU53 inhibits $\mathrm{H}_{2} \mathrm{O}_{2}$-induced spinal cord neuronal apoptosis.

\section{AMPK activation mediates OSU53-induced neuroprotection against $\mathrm{H}_{2} \mathrm{O}_{2}$}

OSU53 is the novel AMPK activator $[15,16]$, the requirement of AMPK in OSU53-meidated neuroprotection was then tested. Western blotting assay results in Figure $3 \mathrm{~A}$ confirmed that OSU53 treatment induced significant AMPK activation in cultured murine spinal cord neurons. AMPK activation was reflected by phosphorylations ("p-") of AMPK $\alpha 1$ (at Thr-172) and acetyl-CoA carboxylase (ACC, Ser-79), the latter is the AMPK's major downstream substrate $[21,22]$. Intriguingly, $\mathrm{H}_{2} \mathrm{O}_{2}$ also induced minor AMPK activation, or AMPK $\alpha 1 /$ ACC phosphorylations (Figure 3A), which was largely enhanced with OSU53 cotreatment (Figure 3A).

To study the link between AMPK activation and OSU53-mediated neuroprotection, pharmacological and genetic strategies were employed to block AMPK activation. Compound $\mathrm{C}$ is a well-established AMPK inhibitor [23]. We here demonstrated that compound $\mathrm{C}$ blocked OSU53-induced AMPK activation, or AMPK $\alpha 1$ / ACC phosphorylations, in $\mathrm{H}_{2} \mathrm{O}_{2}$-treated spinal cord neurons (Figure 3B). Further, siRNA strategy was utilized to knockdown AMPK $\alpha 1$. The applied AMPK $\alpha$ siRNA (Santa Cruz Biotech Co) efficiently downregulated AMPK $\alpha 1$ in the spine cord neurons (Figure 3B). Subsequently, OSU53induced AMPK activation was inhibited (Figure 3B). Remarkably, OSU53-mediated neuroprotection against $\mathrm{H}_{2} \mathrm{O}_{2}$ was almost abolished by Compound $\mathrm{C}$ or AMPK $\alpha 1$ siRNA (Figure 3C and 3D). OSU53 was ineffective to protect spine cord neurons when AMPK was inhibited or silenced (Figure 3C and 3D). These results suggest that AMPK activation is required for OSU53-mediated neuroprotection. It should be noted that Compound $\mathrm{C}$ or AMPK $\alpha 1$ siRNA also exacerbated $\mathrm{H}_{2} \mathrm{O}_{2}$-induced cytotoxicity (Figure 3C and 3D), arguing that AMPK activation by $\mathrm{H}_{2} \mathrm{O}_{2}$ itself is also neuroprotective.

\section{Constitutive activation of AMPK protects spinal cord neurons from $\mathrm{H}_{2} \mathrm{O}_{2}$}

Based on the above-mentioned results, we can speculate that forced-activation of AMPK shall also protect spinal cord neurons from oxidative stress. To test this hypothesis, a constitutive-active AMPK $\alpha 1$ (T172D, caAMPK $\alpha 1$, by Dr. Wang [9]) was transfected to the spinal cord neurons. The caAMPK $\alpha 1$ construct had the constitutive phosphorylation of AMPK $\alpha 1$ at Thr-172, leading to sustained AMPK activation $[9,24]$. Western blotting assay results confirmed expression of caAMPK $\alpha 1$ (tagged with Flag) in the spine cord neurons (Figure 4A). AMPK activation, tested by p-ACC, was significantly increased in caAMPK $\alpha 1$-expressing neurons, even in the presence of $\mathrm{H}_{2} \mathrm{O}_{2}$ (Figure 4A). Remarkably, forced-expression of caAMPK $\alpha 1$ protected the spinal cord neurons from $\mathrm{H}_{2} \mathrm{O}_{2}$ (Figure 4B and 4C). Thus, sustained activation of AMPK by caAMPK $\alpha 1$ mimicked OSU53's actions and protected neurons from oxidative stress. It should be noted that adding OSU53 in caAMPK $\alpha 1$-expressing neurons failed to further inhibit $\mathrm{H}_{2} \mathrm{O}_{2}$-induce damages (Figure 4B and $4 \mathrm{C}$ ). Thus, OSU53 
was ineffective in AMPK-pre-activated neurons, again confirming that AMPK activation is required for OSU53mediated neuroprotection against $\mathrm{H}_{2} \mathrm{O}_{2}$.

\section{OSU53 inhibits $\mathrm{H}_{2} \mathrm{O}_{2}$-induced oxidative stress in spinal cord neurons}

Recent studies have confirmed a cytoprotective function of AMPK under various stress conditions. In particularly, activated AMPK is capable of fighting oxidative stress $[25,26]$. AMPK inhibits reactive oxygen species (ROS) production, thus protecting cells from oxidative stress [27]. Here, we show that treatment with OSU53 also significantly attenuated $\mathrm{H}_{2} \mathrm{O}_{2}$-induced ROS production (DCFH-DA fluorescent dye intensity) in spinal cord neurons (Figure 5A). Consequently, $\mathrm{H}_{2} \mathrm{O}_{2}$-induced lipid peroxidation (Figure 5B) and DNA damages (tested by $\gamma$-H2AX percentage, Figure 5C) were also dramatically alleviated by OSU53 pre-treatment. These results suggest that targeted-activation of AMPK by OSU53
A

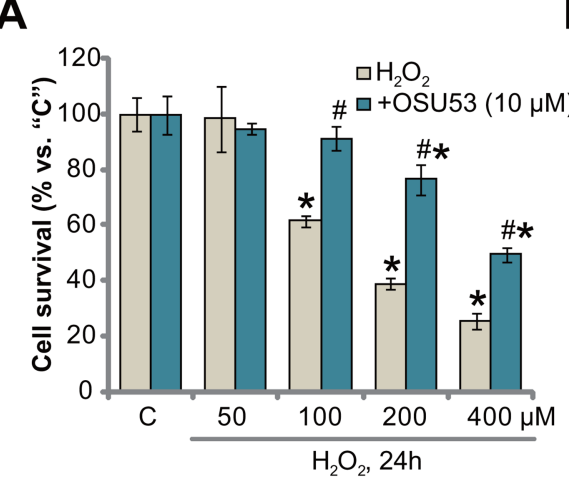

B

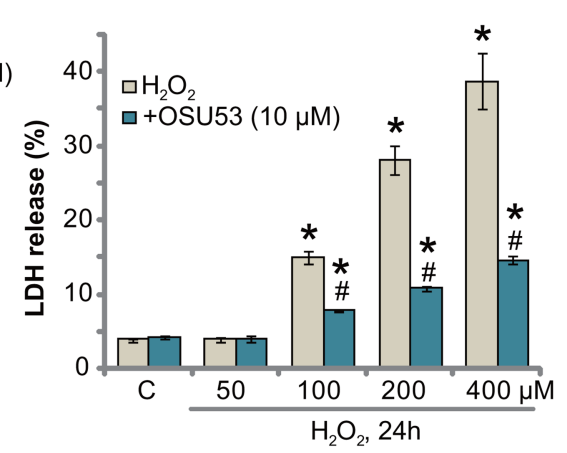

C

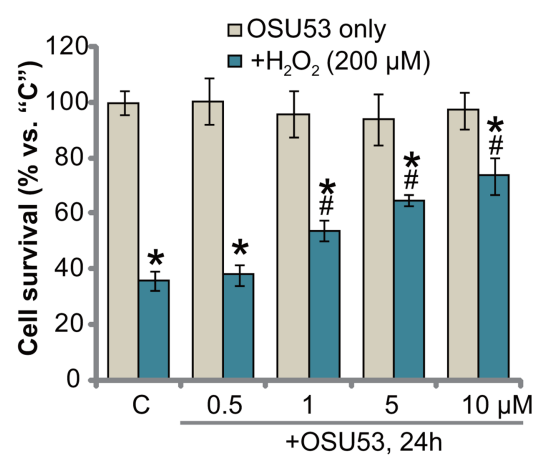

Figure 1: OSU53 protects murine spinal cord neurons from $\mathrm{H}_{2} \mathrm{O}_{2}$. Primary cultured murine spinal cord neurons were treated with hydrogen peroxide $\left(\mathrm{H}_{2} \mathrm{O}_{2}, 50-400 \mu \mathrm{M}\right)$, or plus employed concentration of OSU53, for 24 hours; Neuronal survival and death were tested by CCK-8 assay (A and $\mathbf{C}$ ) and LDH release assay (B), respectively. The data were presented as mean \pm standard deviation (SD) (Same for all Figures). For each assay, $n=5$. "C" stands for untreated control group (Same for all Figures). " $p<0.05$ vs. "C". ${ }^{*} p<0.05$ vs. $\mathrm{H}_{2} \mathrm{O}_{2}$ only group. Experiments in this figure were repeated five times, and similar results were obtained.
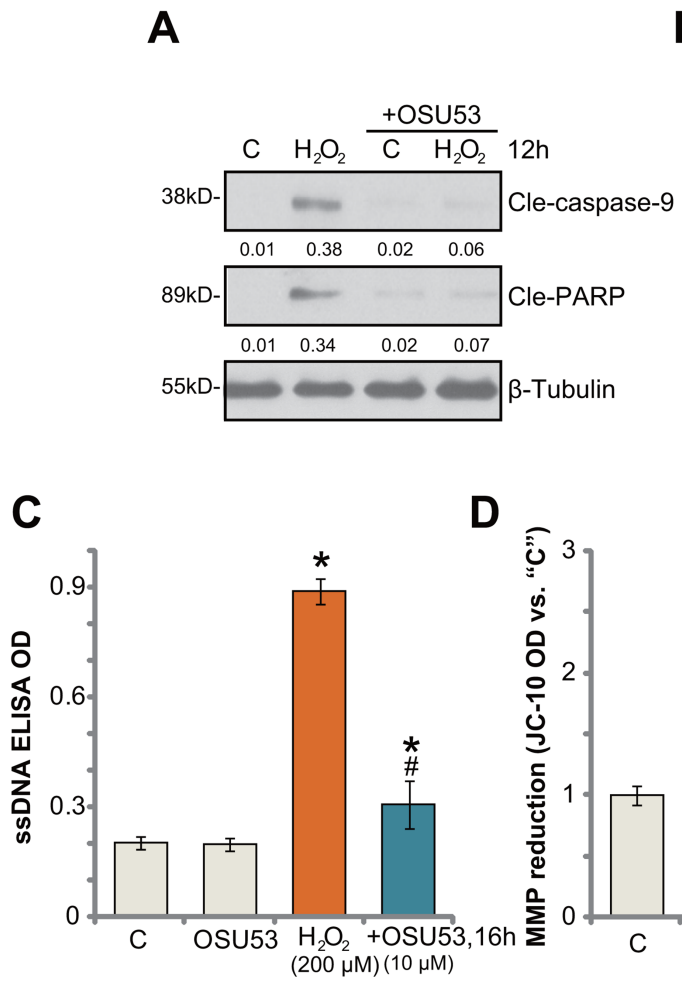

B

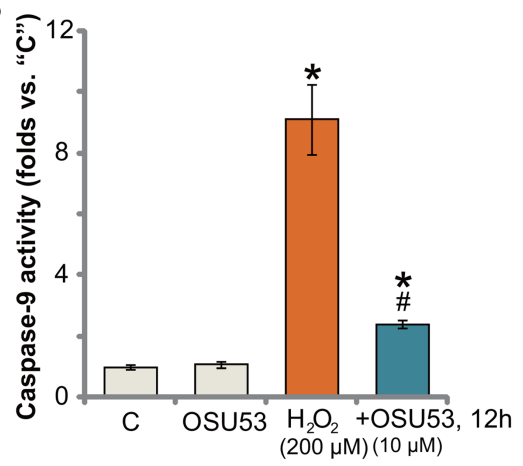

E

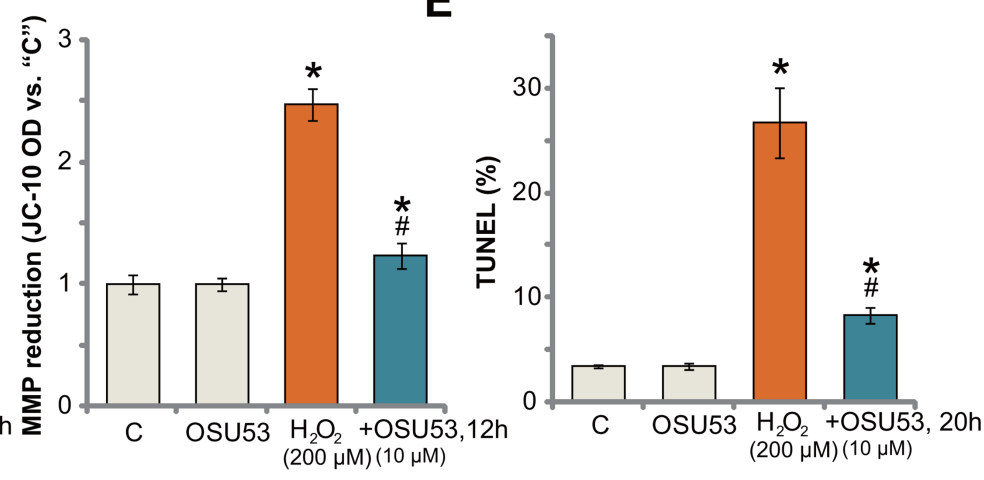

Figure 2: OSU53 inhibits $\mathrm{H}_{2} \mathrm{O}_{2}$-induced spinal cord neuron apoptosis. Primary cultured murine spinal cord neurons were treated with hydrogen peroxide $\left(\mathrm{H}_{2} \mathrm{O}_{2}, 200 \mu \mathrm{M}\right)$, or plus OSU53 $(10 \mu \mathrm{M})$ for indicated time; Cell apoptosis was tested by the assays mentioned in the text (A-E). For each assay, $n=5 .{ }^{*} p<0.05$ vs. "C". ${ }^{*} p<0.05$ vs. $\mathrm{H}_{2} \mathrm{O}_{2}$ only group. Experiments in this figure were repeated three times, and similar results were obtained. 
significantly inhibited $\mathrm{H}_{2} \mathrm{O}_{2}$-oxidative stress in spinal cord neurons, which could be the major reason to explain the neuroprotection activity by this novel AMPK activator.

There are proposed mechanisms responsible for AMPK-mediated anti-oxidant activity. As discussed, AMPK maintains NADPH homeostasis to promote cell survival under stress conditions [7-9, 19, 25]. AMPK is also positively involved in activation of Nrf2 (nuclear factor erythroid 2-related factor 2) [28, 29], the latter is a major anti-oxidant transcription factor responsible for transcription of heme oxygenase (HO)-1 and many other key anti-oxidant genes [30-34]. Here, we show that OSU53 treatment also induced NADPH synthesis in the spinal cord neurons (Figure 5D). More importantly, although $\mathrm{H}_{2} \mathrm{O}_{2}$ decreased NADPH content in the neurons (Figure 5D), after co-treatment OSU53, its level was restored (Figure 5D). Further studies showed that OSU53 treatment in spinal cord neurons also induced transcription of HO-1 mRNA (Figure 5E). Additionally, $\mathrm{H}_{2} \mathrm{O}_{2}$-induced HO-1 $m R N A$ expression was further enhanced with OSU53 co-treatment (Figure 5E). These results suggest that OSU53-mediated anti-oxidant response could be due to AMPK-dependent NADPH production and/or Nrf2HO-1 signaling activation.

\section{DISCUSSION}

In the current study, we show that OSU53 activated AMPK signaling, which is required for its activity in spinal cord neurons. Compound C, the AMPK inhibitor, or AMPK $\alpha 1$ siRNA almost abolished OSU53-mediated neuroprotection against $\mathrm{H}_{2} \mathrm{O}_{2}$. On the other hand, sustainedactivation of AMPK by introducing the ca-AMPK $\alpha 1$ (T172D) mimicked OSU53's actions and protected spinal cord neurons from oxidative stress. More importantly, adding OSU53 was ineffective in ca-AMPK $\alpha 1$-expressing
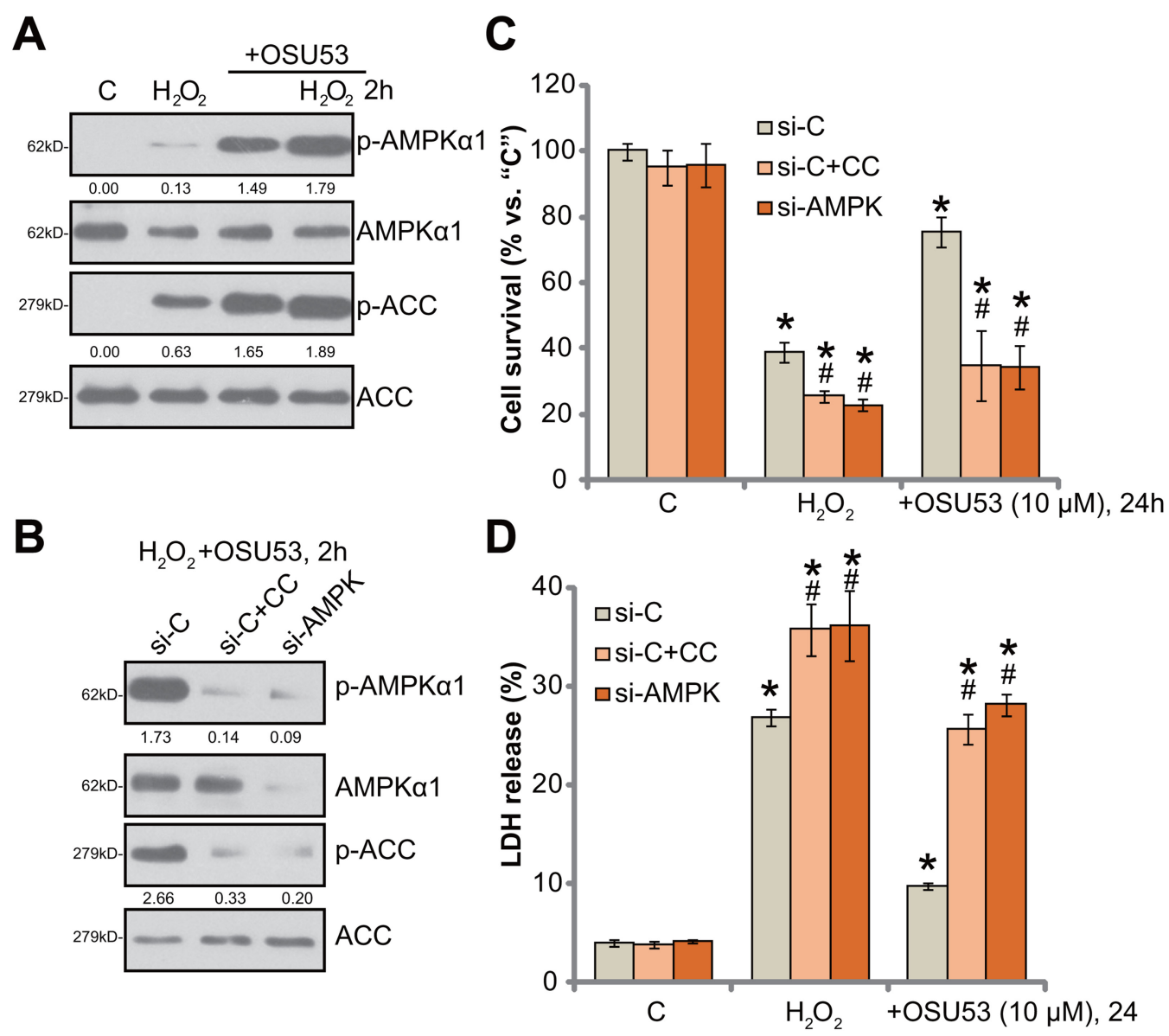

Figure 3: AMPK activation mediates OSU53-induced neuroprotection against $\mathrm{H}_{2} \mathrm{O}_{2}$. Primary cultured murine spinal cord neurons were treated with hydrogen peroxide $\left(\mathrm{H}_{2} \mathrm{O}_{2}, 200 \mu \mathrm{M}\right)$, or plus OSU53 $(10 \mu \mathrm{M})$ for 2 hours, expressions of total and phosphorylated ("p-") AMPK $\alpha 1$ and ACC were shown (A). Phosphorylations AMPK $\alpha 1$ (vs. total AMPK $\alpha 1$ ) and ACC (vs. total ACC) were quantified (A). Primary cultured murine spinal cord neurons, were pretreated with the AMPK inhibitor Compound C (10 $\mu$, for 1 hour) or AMPK 1 siRNA (200 nM, 2 rounds, total 24 hours), followed by hydrogen peroxide $\left(\mathrm{H}_{2} \mathrm{O}_{2}, 200 \mu \mathrm{M}\right)$, or plus OSU53 $(10 \mu \mathrm{M})$ treatment for employed time; Expressions of listed proteins were shown (B), phosphorylations of AMPK $\alpha 1$ (vs. $\beta$-Tubulin) and ACC (vs. total ACC) were quantified (B); Neuronal survival (CCK-8 assay, (C) and death (LDH release assay, (D) were also tested. "si-C" stands for non-sense scramble siRNA (B-D). For each assay, $n=5 .{ }^{*} p<0.05$ vs. "C". " $p<0.05$ vs. "si-C" group. Experiments in this figure were repeated three times, and similar results were obtained. 
neurons against $\mathrm{H}_{2} \mathrm{O}_{2}$. Therefore, targeted-activation of AMPK by OSU53 protects the spinal cord neurons from oxidative stress.
A number of recent studies have proposed the anti-oxidant function of activated AMPK under stress conditions $[7,8,35,36]$. AMPK was initially found to
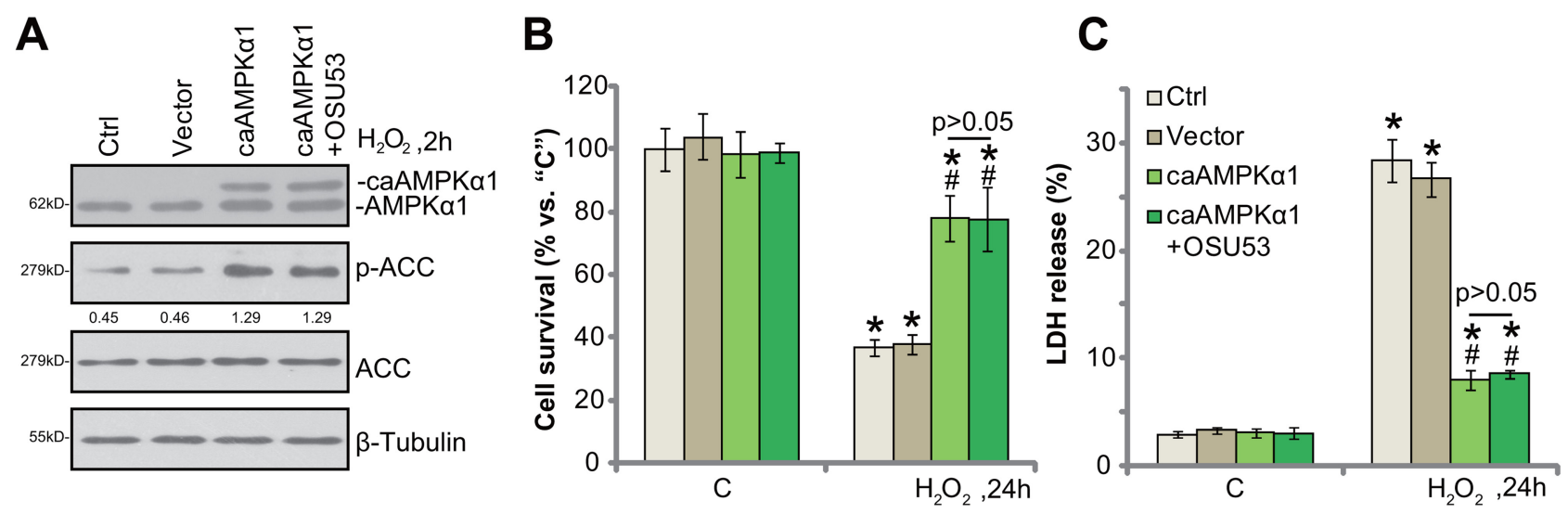

Figure 4: Constitutive activation of AMPK protects spinal cord neurons from $\mathrm{H}_{2} \mathrm{O}_{2}$. The primary cultured murine spinal cord neurons, expressing the constitutive-active AMPK $\alpha 1$ (T172D, "caAMPK $\alpha 1$ ", Flag-tagged) or empty vector (pSuper-puro-Flag, "Vector"), as well as the control neurons ("Ctrl") were treated with hydrogen peroxide $\left(\mathrm{H}_{2} \mathrm{O}_{2}, 200 \mu \mathrm{M}\right)$, or plus OSU53 (10 $\left.\mu \mathrm{M}\right)$ for employed time, total and phosphorylated ("p") AMPK $\alpha 1$ and ACC were shown (A), p-ACC (vs. total ACC) were quantified (A); Neuronal survival (CCK-8 assay, $(\mathbf{B})$ and death (LDH release assay, $(\mathbf{C})$ were also tested. For each assay, $n=5 .{ }^{*} p<0.05$ vs. "C". " $p<0.05$ vs. "Ctrl" cells. Experiments in this figure were repeated three times, and similar results were obtained.

A

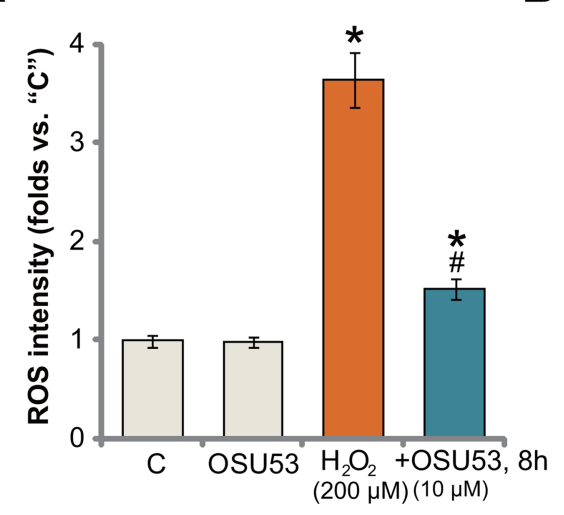

D
B

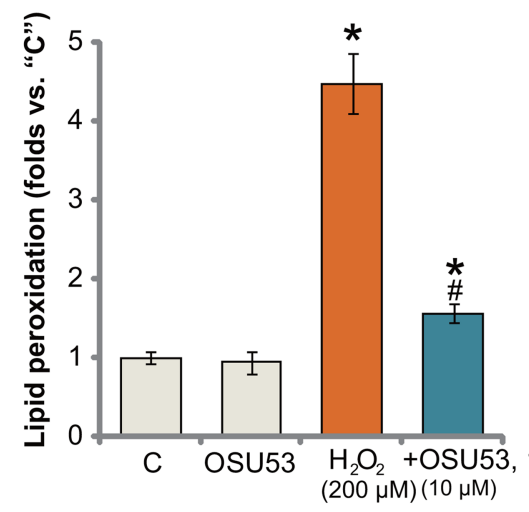

C

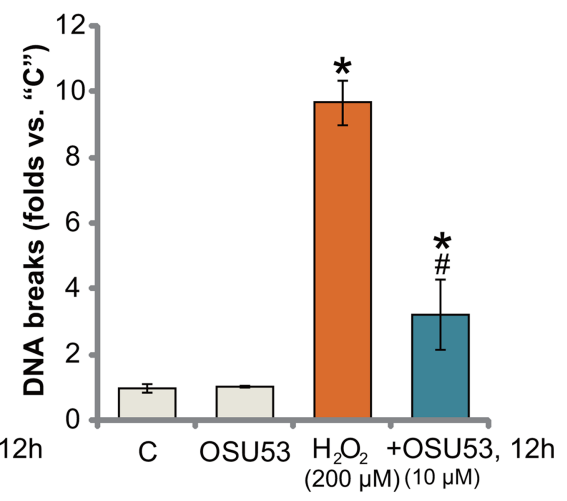

E
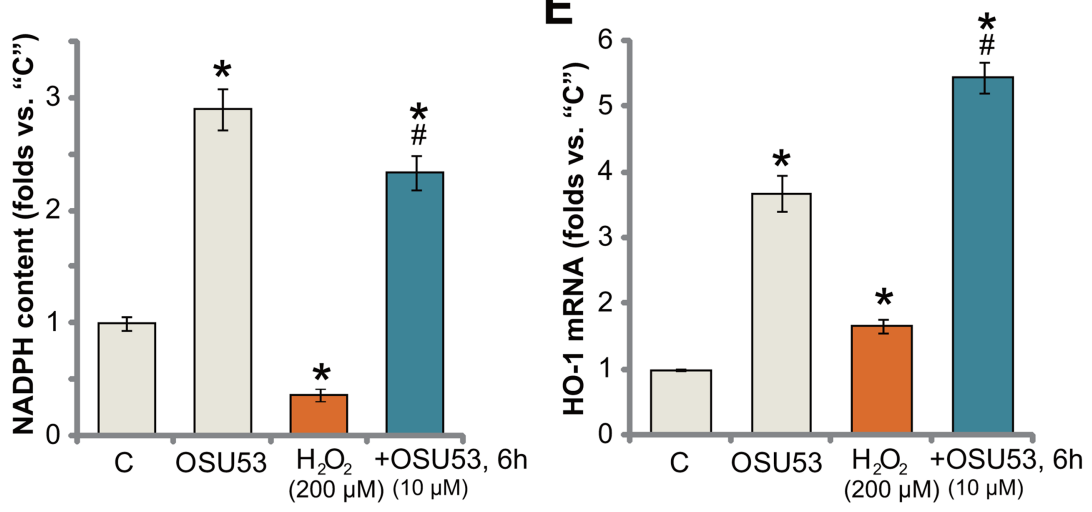

Figure 5: OSU53 inhibits $\mathrm{H}_{2} \mathrm{O}_{2}$-induced oxidative stress in spinal cord neurons. Primary cultured murine spinal cord neurons were treated with hydrogen peroxide $\left(\mathrm{H}_{2} \mathrm{O}_{2}, 200 \mu \mathrm{M}\right)$, or plus OSU53 $(10 \mu \mathrm{M})$ for indicated time; Relative ROS production (A), lipid peroxidation content $(\mathbf{B})$ and DNA damages $(\mathbf{C})$ were tested by the described methods; Relative NADPH content (D) and $H O-1 \mathrm{mRNA}$ expression (E) were also tested. For each assay, $n=5$. ${ }^{*} p<0.05$ vs. "C". ${ }^{\#} p<0.05$ vs. $\mathrm{H}_{2} \mathrm{O}_{2}$ only group. Experiments in this figure were repeated three times, and similar results were obtained. 
be vital for maintaining cellular NADPH content [7]. AMPK phosphorylates and in-activates its major substrate protein ACC, thus reducing NADPH consumption [7]. Additionally, AMPK activation shall promote NADPH synthesis and production [25, 37, 38] through the mechanisms involving fatty-acid oxidation [7]. The study by Guo's group demonstrated that targeted-activation of AMPK by Compound 13, the $\alpha 1$ specific AMPK activator $[39,40]$, increased $\mathrm{NADPH}$ production to inhibit dexamethasone (Dex)-induced oxidative stress, thus offering protection to human osteoblastic cells [36]. Similarly, miR-135b downregulated Ppm1e, the AMPK phosphatase [41-43], to activate AMPK and protect cells from oxidative stress [25]. Here, we show that targetedactivation of AMPK by OSU53 also increased NADPH content in the spinal cord neurons. More importantly, co-treatment with the novel AMPK activator also restored $\mathrm{NADPH}$ content in $\mathrm{H}_{2} \mathrm{O}_{2}$-treated neurons. Thus, AMPKmediated NADPH axis could be one key mechanism responsible for OSU53-mediated neuroprotection against oxidative stress.

Nrf2 is arguably one of the most important antioxidant signaling in mammalian cells [44-46]. As a transcription factor, Nrf2 binds to antioxidant-responsive element (ARE), dictating transcription of multiple key anti-oxidative enzymes [44-46], including HO-1, NAD(P) $\mathrm{H}$ quinone oxidoreductase 1 (NQO1), $\gamma$-glutamyl cysteine ligase catalytic subunit (GCLC) [47], along with many others [44-46]. Recent studies have explored the potential cross-talk between AMPK and Nrf2/HO-1 signalings. It has been shown that activated AMPK could boost the Nrf2/HO-1 signaling axis involving unfolded protein response [28]. Meanwhile, Joo et al., showed that AMPK directly phosphorylates Nrf2 at the Ser-550, which shall promote Nrf2 nuclear accumulation and following HO-1 transcription with the help from GSK3 inhibition [29]. Therefore, AMPK-boosted Nrf2/HO-1 activation could be another key mechanism underlying its anti-oxidant activity. Indeed, we show that $H O-1 \mathrm{mRNA}$ level was significantly increased in OSU53-treated spinal cord neurons. The detailed mechanisms, of course, warrant further characterizations.

It is estimated that there will over 150,000200,000 cases of traumatic spinal cord injury annually due to accidents and violence $[1,2,4]$. The clinical and bench results have indicated that severity of neurological deficit is not solely dependent on the degree of the mechanical insults $[1,2,4]$. It is, interestingly, very closely associated with secondary damaging factors, including ischaemia, oedema, inflammatory response and most importantly oxidative stress $[1,2,4]$. The results of this study suggest that targeted-activation of AMPK by OSU53 efficiently protects the spinal cord neurons from oxidative stress, suggesting that this novel AMPK activator might be further tested in animal and clinical models of spinal cord injury.

\section{MATERIALS AND METHODS}

\section{Reagents and antibodies}

OSU53 was provided by Dr. Cui [19], which was dissolved in dimethyl sulfoxide (DMSO). $\mathrm{H}_{2} \mathrm{O}_{2}$ and compound $\mathrm{C}$ were obtained from Sigma Aldrich Co. (Shanghai, China). Antibodies of p-AMPK $\alpha 1$ (Thr172, \#2531, 1: 1000), AMPKa (\#2532, 1: 2000), acetyl-CoA Carboxylase (ACC, \#3662, 1: 2000), p-ACC (Ser79, \#3661, 1: 1000) and ( $\beta-$ ) Tubulin ( $\# 2146,1: 20,000)$ were purchased from Cell Signaling Technology (Beverly, MA). The cell culture reagents were provided by GIBCO (Rockville, MD).

\section{Murine spinal cord neurons}

The detailed protocol of culture of primary murine spinal cord neurons was described in detail previously [48]. In brief, the spinal cord of C57BL/6J mouse embryos (E13-14) were initially plated at 200,000 cells $/ \mathrm{mL}$ onto the tissue-culture plate, pre-coated with poly-l-lysine (Sigma). The neuronal feeding medium, 90\% MEM, 5\% horse serum, $5 \%$ fetal bovine serum (FBS) (GIBCO), and a mixture of nutrient supplements [48], was replaced with feeding medium every $2-3$ days.

\section{Survival assay}

The Cell Counting Kit-8 (CCK-8) kit, purchased from the Dojindo Laboratories (Kumamoto, Japan), was employed to examine the viability of spinal cord neurons. CCK-8 optic density (OD, at $450 \mathrm{~nm}$ ) of treatment group was always normalized to that of untreated control group.

\section{Death assay}

The release of lactate dehydrogenase (LDH) to the conditional medium is a well-established marker of neuronal cell death, which was tested by a commercial available twostep LDH assay kit (Takara, Tokyo, Japan) [49].

\section{Enzyme-linked immunosorbent assay (ELISA) of cell apoptosis}

The increased production of single stream DNA (ssDNA) is a characteristic marker of cell apoptosis [50]. ssDNA content in spinal cord neurons was tested by a commercial available ssDNA ELISA kit (Chemicon International, Temecula, CA). ELISA OD (at $405 \mathrm{~nm}$ ) was recorded to reflect cell apoptosis.

\section{TUNEL assay}

Spinal cord neurons with described treatment were stained with TUNEL and DAPI florescence dyes (All purchased from Sigma). TUNEL staining ratio (vs. DAPI nuclei number) was recorded. 


\section{Caspase-9 activity assay and mitochondrial depolarization assay}

The caspase- 9 activity assay by the caspase-Glo 9 kit (Promega, Shanghai, China) and mitochondrial membrane potential (MMP) reduction assay by the JC-1 dye (Invitrogen, Shanghai, China) were described in detail in previous studies [20,51].

\section{Western blotting assay}

Spinal cord neurons were first trypsinized and washed. Neurons were then incubated with the cell lysis buffer (Biyuntian, Wuxi, China). Protein concentration was determined using the Bio-Rad protein assay kit (Shanghai, China). For each single treatment, exact $30-40 \mu \mathrm{g}$ total lysate proteins (per lane) were separated by the SDS-PAGE gels $(7.5-10 \%)[52,53]$, which were then transferred to the PVDF blots (Millipore, Suzhou, China). After blocking, the blots were incubated with designated primary and secondary antibodies. To visualize the targeted bands, the enhanced chemiluminescence (ECL) reagents (Pierce) were added, and X-Ray film development was employed.

\section{qRT-PCR assay}

Spinal cord neurons were incubated with TRIzol reagents (Invitrogen) to achieve total cellular RNA. Quantitative Real-time PCR ("qRT-PCR") assay was performed BY the SYBR green kit on the ABI-7600 fast PCR system (Applied Biosystems, Shanghai, China) [33]. mRNA primers for murine $H O-1$ and $G A P D H$ were described previously [47, 54]. GAPDH $m R N A$ was always tested as the internal control and reference gene. The $2^{-\Delta \Delta C t}$ method was employed to calculate relative $H O-1 \mathrm{mRNA}$ expression (vs. GAPDH $m R N A$ ).

\section{SiRNA}

The siRNA of murine AMPK $\alpha 1$ was purchased from Santa Cruz Biotech. The AMPK $\alpha 1$ siRNA or the scramble control siRNA ( $200 \mathrm{nM}, 12$ hours $\times$ two rounds) transfection to spinal cord neurons was performed using the Lipofectamine 2000 reagent (Invitrogen). Afterwards, AMPK $\alpha 1$ knockdown in the resulting neurons was verified by Western blotting assay.

\section{AMPKo1 mutation}

The constitutive-active AMPK $\alpha 1$ (T172D, caAMPK $\alpha 1$ ) was provided by Dr. Wang at Soochow University [9]. The spinal cord neurons were seeded onto 6-well plates at $50-60 \%$ confluence. The caAMPK $\alpha 1$ cDNA $(0.25 \mu \mathrm{g}$ per well) was transfected to neurons via the Lipofectamine 2000 protocol [55]. Transfection efficiency was always verified via Western blotting assay.

\section{NADPH assay}

The NADPH content was tested via the methods described previously $[8,56]$. Spinal cord neurons with the described treatment were trypsinized and washed with PBS, and incubated with the lysis buffer (Biyuntian, Wuxi, China). The protein lysates were then incubated with NADP-cycling buffer along with glucose-6-phosphate dehydrogenase (G6PD, Sigma) at $60^{\circ} \mathrm{C}$ for $30 \mathrm{~min}$ [8], which was followed by addition of glucose 6-phosphate (G6P, Sigma). Thereafter, G6P's absorbance change at $570 \mathrm{~nm}$ was tested every 30 seconds for $4 \mathrm{~min}$. NADPH content was then recorded and normalized to that of untreated control group [56].

\section{Reactive oxygen species (ROS) assay}

The dichlorofluorescin diacetate (DCFH-DA) fluorescent dye (Invitrogen) was employed to quantify cellular ROS intensity [25]. In brief, $1 \mu \mathrm{M}$ of DCFH-DA were added to the cultured spinal cord neurons for $45 \mathrm{~min}$. Neurons were then washedS, and subjected to examination of fluorescence intensity under a Fluorescence Microplate Reader (Synergy 2, BioTek, Winooski, VT). ROS intensity OD was expressed as fold change of untreated control group.

\section{Lipid peroxidation assay}

The thiobarbituric acid reactive substances (TBAR) assay was employed to test the cellular lipid peroxidation intensity. The detailed protocol was described previously $[57,58]$.

\section{DNA damage assay}

In the current study, $\gamma-\mathrm{H} 2 \mathrm{AX}$ intensity was tested to reflect cellular DNA damages [59]. In short, spinal cord neurons with the applied treatment were trypsinized and fixed. Afterwards, anti- $\gamma-\mathrm{H} 2 \mathrm{AX}$ antibody (Cellular Signaling Tech) was added to the neurons for additional 4 hours. The FITC-conjugated secondary antibody was then added to the $\gamma-\mathrm{H} 2 \mathrm{AX}$-labbled neurons, which were then subjected to FACS assay. $\gamma$-H2AX percentage was recorded [59].

\section{Statistical analysis}

The results were expressed as mean \pm standard deviation (SD). The statistical analysis among different groups was done using one-way ANOVA with Scheffe's test. Experiments were repeated at least three times and consistent results were always obtained.

\section{Author contributions}

All listed authors have contributed significantly to the study. 


\section{ACKNOWLEDGMENTS}

This study was partly supported by Shanghai Minhang District natural science research project (2015MHZ011 to X.F.).

\section{CONFLICTS OF INTEREST}

The authors declare no conflict of interests.

\section{REFERENCES}

1. Siddiqui AM, Khazaei M, Fehlings MG. Translating mechanisms of neuroprotection, regeneration, and repair to treatment of spinal cord injury. Prog Brain Res. 2015; 218:15-54. https://doi.org/10.1016/bs.pbr.2014.12.007.

2. Fatima G, Sharma VP, Das SK, Mahdi AA. Oxidative stress and antioxidative parameters in patients with spinal cord injury: implications in the pathogenesis of disease. Spinal Cord. 2015; 53:3-6. https://doi.org/10.1038/sc.2014.178.

3. Lam T, Chen Z, Sayed-Ahmed MM, Krassioukov A, Al-Yahya AA. Potential role of oxidative stress on the prescription of rehabilitation interventions in spinal cord injury. Spinal Cord. 2013; 51:656-62. https://doi. org/10.1038/sc.2013.71.

4. Ahuja CS, Wilson JR, Nori S, Kotter MR, Druschel C, Curt A, Fehlings MG. Traumatic spinal cord injury. Nat Rev Dis Primers. 2017; 3:17018. https://doi.org/10.1038/ nrdp.2017.18.

5. Hardie DG, Ross FA, Hawley SA. AMPK: a nutrient and energy sensor that maintains energy homeostasis. Nat Rev Mol Cell Biol. 2012; 13:251-62. https://doi.org/10.1038/ nrm3311.

6. Mihaylova MM, Shaw RJ. The AMPK signalling pathway coordinates cell growth, autophagy and metabolism. Nat Cell Biol. 2011; 13:1016-23. https://doi.org/10.1038/ ncb2329.

7. Jeon SM, Chandel NS, Hay N. AMPK regulates NADPH homeostasis to promote tumour cell survival during energy stress. Nature. 2012; 485:661-65. https://doi.org/10.1038/ nature11066.

8. She C, Zhu LQ, Zhen YF, Wang XD, Dong QR. Activation of AMPK protects against hydrogen peroxide-induced osteoblast apoptosis through autophagy induction and NADPH maintenance: new implications for osteonecrosis treatment? Cell Signal. 2014; 26:1-8. https://doi. org/10.1016/j.cellsig.2013.08.046.

9. Guo S, Mao L, Ji F, Wang S, Xie Y, Fei H, Wang XD. Activating AMP-activated protein kinase by an $\alpha 1$ selective activator compound 13 attenuates dexamethasone-induced osteoblast cell death. Biochem Biophys Res Commun. 2016; 471:545-52. https://doi.org/10.1016/j.bbrc.2016.02.036.

10. Egan DF, Shackelford DB, Mihaylova MM, Gelino S, Kohnz RA, Mair W, Vasquez DS, Joshi A, Gwinn
DM, Taylor R, Asara JM, Fitzpatrick J, Dillin A, et al. Phosphorylation of ULK1 (hATG1) by AMP-activated protein kinase connects energy sensing to mitophagy. Science. 2011; 331:456-61. https://doi.org/10.1126/ science. 1196371.

11. Zhu Y, Zhou J, Ao R, Yu B. A-769662 protects osteoblasts from hydrogen dioxide-induced apoptosis through activating of AMP-activated protein kinase (AMPK). Int J Mol Sci. 2014; 15:11190-203. https://doi.org/10.3390/ ijms 150611190 .

12. Guh JH, Chang WL, Yang J, Lee SL, Wei S, Wang D, Kulp SK, Chen CS. Development of novel adenosine monophosphate-activated protein kinase activators. J Med Chem. 2010; 53:2552-61. https://doi.org/10.1021/ jm901773d.

13. Kimura N, Tokunaga C, Dalal S, Richardson C, Yoshino K, Hara K, Kemp BE, Witters LA, Mimura O, Yonezawa K. A possible linkage between AMP-activated protein kinase (AMPK) and mammalian target of rapamycin (mTOR) signalling pathway. Genes Cells. 2003; 8:65-79. https://doi. org/10.1046/j.1365-2443.2003.00615.x.

14. Hawley SA, Fullerton MD, Ross FA, Schertzer JD, Chevtzoff C, Walker KJ, Peggie MW, Zibrova D, Green KA, Mustard KJ, Kemp BE, Sakamoto K, Steinberg GR, Hardie DG. The ancient drug salicylate directly activates AMP-activated protein kinase. Science. 2012; 336:918-22. https://doi.org/10.1126/science.1215327.

15. Plews RL, Mohd Yusof A, Wang C, Saji M, Zhang X, Chen CS, Ringel MD, Phay JE. A novel dual AMPK activator/ mTOR inhibitor inhibits thyroid cancer cell growth. J Clin Endocrinol Metab. 2015; 100:E748-56. https://doi. org/10.1210/jc.2014-1777.

16. Chou CC, Lee KH, Lai IL, Wang D, Mo X, Kulp SK, Shapiro CL, Chen CS. AMPK reverses the mesenchymal phenotype of cancer cells by targeting the Akt-MDM2Foxo3a signaling axis. Cancer Res. 2014; 74:4783-95. https://doi.org/10.1158/0008-5472.CAN-14-0135.

17. Lee KH, Hsu EC, Guh JH, Yang HC, Wang D, Kulp SK, Shapiro CL, Chen CS. Targeting energy metabolic and oncogenic signaling pathways in triple-negative breast cancer by a novel adenosine monophosphate-activated protein kinase (AMPK) activator. J Biol Chem. 2011; 286:39247-58. https://doi.org/10.1074/jbc.M111.264598.

18. Trikha P, Plews RL, Stiff A, Gautam S, Hsu V, Abood D, Wesolowski R, Landi I, Mo X, Phay J, Chen CS, Byrd J, Caligiuri $\mathrm{M}$, et al. Targeting myeloid-derived suppressor cells using a novel adenosine monophosphate-activated protein kinase (AMPK) activator. OncoImmunology. 2016; 5:e1214787. https://doi.org/10.1080/2162402X.2016.1214787.

19. Xu D, Zhao W, Zhu X, Fan J, Cui S, Sun Y, Chen X, Liu W, Cui ZM. OSU53 Rescues Human OB-6 Osteoblastic Cells from Dexamethasone through Activating AMPK Signaling. PLoS One. 2016; 11:e0162694. https://doi.org/10.1371/ journal.pone.0162694. 
20. Dong YY, Zhuang YH, Cai WJ, Liu Y, Zou WB. The mitochondrion interfering compound NPC-26 exerts potent anti-pancreatic cancer cell activity in vitro and in vivo. Tumour Biol. 2016; 37:15053-63. https://doi.org/10.1007/ s13277-016-5403-5.

21. Minokoshi Y, Kim YB, Peroni OD, Fryer LG, Müller C, Carling D, Kahn BB. Leptin stimulates fatty-acid oxidation by activating AMP-activated protein kinase. Nature. 2002; 415:339-43. https://doi.org/10.1038/415339a.

22. Tomas E, Tsao TS, Saha AK, Murrey HE, Zhang C, Itani SI, Lodish HF, Ruderman NB. Enhanced muscle fat oxidation and glucose transport by ACRP30 globular domain: acetyl-CoA carboxylase inhibition and AMP-activated protein kinase activation. Proc Natl Acad Sci USA. 2002; 99:16309-13. https://doi.org/10.1073/pnas.222657499.

23. Jin J, Mullen TD, Hou Q, Bielawski J, Bielawska A, Zhang X, Obeid LM, Hannun YA, Hsu YT. AMPK inhibitor Compound $\mathrm{C}$ stimulates ceramide production and promotes Bax redistribution and apoptosis in MCF7 breast carcinoma cells. J Lipid Res. 2009; 50:2389-97. https://doi. org/10.1194/jlr.M900119-JLR200.

24. Wu YH, Li Q, Li P, Liu B. GSK621 activates AMPK signaling to inhibit LPS-induced TNF $\alpha$ production. Biochem Biophys Res Commun. 2016; 480:289-95. https:// doi.org/10.1016/j.bbrc.2016.10.001.

25. Fan JB, Ruan JW, Liu W, Zhu LQ, Zhu XH, Yi H, Cui SY, Zhao JN, Cui ZM. miR-135b expression downregulates Ppm1e to activate AMPK signaling and protect osteoblastic cells from dexamethasone. Oncotarget. 2016; 7:70613-22. https://doi.org/10.18632/oncotarget.12138.

26. Fan JB, Liu W, Zhu XH, Yi H, Cui SY, Zhao JN, Cui ZM. microRNA-25 targets $\mathrm{PKC} \zeta$ and protects osteoblastic cells from dexamethasone via activating AMPK signaling. Oncotarget. 2017; 8:3226-36. https://doi.org/10.18632/ oncotarget.12138.

27. Law BY, Mok SW, Chan WK, Xu SW, Wu AG, Yao XJ, Wang JR, Liu L, Wong VK. Hernandezine, a novel AMPK activator induces autophagic cell death in drug-resistant cancers. Oncotarget. 2016; 7:8090-104. https://doi. org/10.18632/oncotarget.6980.

28. Zimmermann K, Baldinger J, Mayerhofer B, Atanasov AG, Dirsch VM, Heiss EH. Activated AMPK boosts the Nrf2/HO-1 signaling axis--A role for the unfolded protein response. Free Radic Biol Med. 2015; 88:417-26. https:// doi.org/10.1016/j.freeradbiomed.2015.03.030.

29. Joo MS, Kim WD, Lee KY, Kim JH, Koo JH, Kim SG. AMPK Facilitates Nuclear Accumulation of Nrf2 by Phosphorylating at Serine 550. Mol Cell Biol. 2016; 36:1931-42. https://doi.org/10.1128/MCB.00118-16.

30. Tung MC, Lin PL, Wang YC, He TY, Lee MC, Yeh SD, Chen CY, Lee H. Mutant p53 confers chemoresistance in non-small cell lung cancer by upregulating Nrf2. Oncotarget. 2015; 6:41692-705. https://doi.org/10.18632/oncotarget.6150.

31. Ryoo IG, Choi BH, Kwak MK. Activation of NRF2 by p62 and proteasome reduction in sphere-forming breast carcinoma cells. Oncotarget. 2015; 6:8167-84. https://doi. org/10.18632/oncotarget.3047.

32. Ning S, Sekar TV, Scicinski J, Oronsky B, Peehl DM, Knox SJ, Paulmurugan R. Nrf2 activity as a potential biomarker for the pan-epigenetic anticancer agent, RRx-001. Oncotarget. 2015; 6:21547-56. https://doi.org/10.18632/ oncotarget.4249.

33. Gong YQ, Huang W, Li KR, Liu YY, Cao GF, Cao C, Jiang Q. SC79 protects retinal pigment epithelium cells from UV radiation via activating Akt-Nrf2 signaling. Oncotarget. 2016; 7:60123-32. https://doi.org/10.18632/ oncotarget.11164.

34. Chen Z, Zhang Y, Ma L, Ni Y, Zhao H. Nrf2 plays a pivotal role in protection against burn trauma-induced intestinal injury and death. Oncotarget. 2016; 7:19272-83. https:// doi.org/10.18632/oncotarget.8189.

35. Zheng K, Lu H, Sheng Z, Li Y, Xu B. Low-concentration of perifosine surprisingly protects cardiomyocytes from oxygen glucose deprivation. Biochem Biophys Res Commun. 2016; 469:753-60. https://doi.org/10.1016/j. bbrc.2015.12.014.

36. Guo S, Mao L, Ji F, Wang S, Xie Y, Fei H, Wang XD. Activating AMP-activated protein kinase by an $\alpha 1$ selective activator compound 13 attenuates dexamethasone-induced osteoblast cell death. Biochem Biophys Res Commun. 2016; 471:545-52. https://doi.org/10.1016/j.bbrc.2016.02.036.

37. Zhang YH, Cheng F, Du XT, Gao JL, Xiao XL, Li N, Li SL, Dong L. GDF11/BMP11 activates both smad1/5/8 and smad $2 / 3$ signals but shows no significant effect on proliferation and migration of human umbilical vein endothelial cells. Oncotarget. 2016; 7:12063-74. https:// doi.org/10.18632/oncotarget.7642.

38. Wang MD, Wu H, Huang S, Zhang HL, Qin CJ, Zhao LH, Fu GB, Zhou X, Wang XM, Tang L, Wen W, Yang W, Tang $\mathrm{SH}$, et al. HBx regulates fatty acid oxidation to promote hepatocellular carcinoma survival during metabolic stress. Oncotarget. 2016; 7:6711-26. https://doi.org/10.18632/ oncotarget. 6817.

39. Zhao H, Zhu H, Lin Z, Lin G, Lv G. Compound 13, an $\alpha 1$-selective small molecule activator of AMPK, inhibits Helicobacter pylori-induced oxidative stresses and gastric epithelial cell apoptosis. Biochem Biophys Res Commun. 2015; 463:510-17. https://doi.org/10.1016/j. bbrc.2015.05.059.

40. Hu X, Jiang F, Bao Q, Qian H, Fang Q, Shao Z. Compound 13, an $\alpha 1$-selective small molecule activator of AMPK, potently inhibits melanoma cell proliferation. Tumour Biol. 2016; 37:1071-78. https://doi.org/10.1007/s13277-0153854-8.

41. Voss M, Paterson J, Kelsall IR, Martín-Granados C, Hastie CJ, Peggie MW, Cohen PT. Ppm1E is an in cellulo AMPactivated protein kinase phosphatase. Cell Signal. 2011; 23:114-24. https://doi.org/10.1016/j.cellsig.2010.08.010.

42. Li ZW, Zhu YR, Zhou XZ, Zhuo BB, Wang XD. microRNA-135b expression silences Ppmle to provoke 
AMPK activation and inhibit osteoblastoma cell proliferation. Oncotarget. 2017; 8:26424-33. https://doi. org/10.18632/oncotarget.15477.

43. Chen MB, Liu YY, Cheng LB, Lu JW, Zeng P, Lu PH. $\mathrm{AMPK} \alpha$ phosphatase Ppm1E upregulation in human gastric cancer is required for cell proliferation. Oncotarget. 2017; 8:31288-96. https://doi.org/10.18632/oncotarget.16126

44. Suzuki T, Yamamoto M. Molecular basis of the Keap1-Nrf2 system. Free Radic Biol Med. 2015; 88:93-100. https://doi. org/10.1016/j.freeradbiomed.2015.06.006.

45. Li W, Kong AN. Molecular mechanisms of Nrf2-mediated antioxidant response. Mol Carcinog. 2009; 48:91-104. https://doi.org/10.1002/mc.20465.

46. Itoh K, Tong KI, Yamamoto M. Molecular mechanism activating Nrf2-Keap1 pathway in regulation of adaptive response to electrophiles. Free Radic Biol Med. 2004; 36:1208-13. https://doi.org/10.1016/j. freeradbiomed.2004.02.075.

47. Li KR, Yang SQ, Gong YQ, Yang H, Li XM, Zhao YX, Yao J, Jiang Q, Cao C. 3H-1,2-dithiole-3-thione protects retinal pigment epithelium cells against Ultra-violet radiation via activation of Akt-mTORC1-dependent Nrf2-HO-1 signaling. Sci Rep. 2016; 6:25525. https://doi.org/10.1038/ srep25525.

48. Mariqueo TA, Agurto A, Muñoz B, San Martin L, Coronado C, Fernández-Pérez EJ, Murath P, Sánchez A, Homanics GE, Aguayo LG. Effects of ethanol on glycinergic synaptic currents in mouse spinal cord neurons. J Neurophysiol. 2014; 111:1940-48. https://doi.org/10.1152/jn.00789.2013

49. Ji F, Mao L, Liu Y, Cao X, Xie Y, Wang S, Fei H. K6PC-5, a novel sphingosine kinase 1 (SphK1) activator, alleviates dexamethasone-induced damages to osteoblasts through activating SphK1-Akt signaling. Biochem Biophys Res Commun. 2015; 458:568-75. https://doi.org/10.1016/j. bbrc.2015.02.007.

50. Frankfurt OS, Krishan A. Enzyme-linked immunosorbent assay (ELISA) for the specific detection of apoptotic cells and its application to rapid drug screening. J Immunol Methods. 2001; 253:133-44. https://doi.org/10.1016/S00221759(01)00387-8.

51. Ju T, Gao D, Fang ZY. Targeting colorectal cancer cells by a novel sphingosine kinase 1 inhibitor PF-543. Biochem Biophys Res Commun. 2016; 470:728-34. https://doi. org/10.1016/j.bbrc.2016.01.053.
52. Leyh B, Dittmer A, Lange T, Martens JW, Dittmer J. Stromal cells promote anti-estrogen resistance of breast cancer cells through an insulin-like growth factor binding protein 5 (IGFBP5)/B-cell leukemia/lymphoma 3 (Bcl-3) axis. Oncotarget. 2015; 6:39307-28. https://doi. org/10.18632/oncotarget.5624.

53. Canella A, Cordero Nieves H, Sborov DW, Cascione L, Radomska HS, Smith E, Stiff A, Consiglio J, Caserta E, Rizzotto L, Zanesi N, Stefano V, Kaur B, et al. HDAC inhibitor AR-42 decreases CD44 expression and sensitizes myeloma cells to lenalidomide. Oncotarget. 2015; 6:3113450. https://doi.org/10.18632/oncotarget.5290.

54. Zhang H, Liu YY, Jiang Q, Li KR, Zhao YX, Cao C, Yao J. Salvianolic acid A protects RPE cells against oxidative stress through activation of Nrf2/HO-1 signaling. Free Radic Biol Med. 2014; 69:219-28. https://doi.org/10.1016/j. freeradbiomed.2014.01.025.

55. Lu PH, Chen MB, Ji C, Li WT, Wei MX, Wu MH. Aqueous Oldenlandia diffusa extracts inhibits colorectal cancer cells via activating AMP-activated protein kinase signalings. Oncotarget. 2016; 7:45889-900. https://doi.org/10.18632/ oncotarget.9969.

56. Hu X, Jiang F, Bao Q, Qian H, Fang Q, Shao Z. Compound 13, an $\alpha 1$-selective small molecule activator of AMPK, potently inhibits melanoma cell proliferation. Tumour Biol. 2016; 37:1071-78. https://doi.org/10.1007/s13277-0153854-8.

57. Kwon MY, Park E, Lee SJ, Chung SW. Heme oxygenase-1 accelerates erastin-induced ferroptotic cell death. Oncotarget. 2015; 6:24393-403. https://doi.org/10.18632/ oncotarget.5162.

58. Cortizo AM, Bruzzone L, Molinuevo S, Etcheverry SB. A possible role of oxidative stress in the vanadium-induced cytotoxicity in the MC3T3E1 osteoblast and UMR106 osteosarcoma cell lines. Toxicology. 2000; 147:89-99. https://doi.org/10.1016/S0300-483X(00)00181-5.

59. Ewald B, Sampath D, Plunkett W. H2AX phosphorylation marks gemcitabine-induced stalled replication forks and their collapse upon S-phase checkpoint abrogation. Mol Cancer Ther. 2007; 6:1239-48. https://doi. org/10.1158/1535-7163.MCT-06-0633. 